\title{
The impact of admission red cell distribution width on long-term cardiovascular events after primary percutaneous intervention: A four-year prospective study
}

\author{
Turgay Isik ${ }^{1}$, Mustafa Kurt ${ }^{2}$, Ibrahim Halil Tanboga ${ }^{3}$, Erkan Ayhan ${ }^{1}$, \\ Zeki Yuksel Gunaydin ${ }^{4}$, Ahmet Kaya ${ }^{4}$, Huseyin Uyarel $^{5}$ \\ ${ }^{1}$ Department of Cardiology, Balikesir University, School of Medicine, Balikesir, Turkey \\ ${ }^{2}$ Department of Cardiology, Mustafa Kemal University, School of Medicine, Hatay, Turkey \\ ${ }^{3}$ Department of Cardiology, Ataturk University, School of Medicine, Erzurum, Turkey \\ ${ }^{4}$ Department of Cardiology, Ordu University, School of Medicine, Ordu, Turkey \\ ${ }^{5}$ Department of Cardiology, Bezmialem University, School of Medicine, Istanbul, Turkey
}

\begin{abstract}
Background: Red cell distribution width $(R D W)$ is an indicator of erythrocyte in different size, and its prognostic value has been demonstrated in numerous cardiac and non-cardiac diseases. The purpose of this study was to evaluate the predictive value of $R D W$ on the long-term cardiovascular events in patients undergoing primary percutaneous coronary intervention (PCI).
\end{abstract}

Methods: Ninety-six consecutive patients (mean age $60.6 \pm 12.5$ years, $77.1 \%$ male) with ST-segment elevation myocardial infarction (STEMI), who were treated with primary PCI, were analyzed prospectively. Baseline RDW and high sensitive C-reactive protein (hs-CRP) were measured. The patients were followed up for major adverse cardiac events (MACE) for up to 48 months after discharge.

Results: There were 30 patients with long-term MACE (Group 1) and 66 patients without long-term MACE (Group 2). Age, admission RDW, hs-CRP and creatine kinase-MB levels, heart rate after PCI, previously used angiotensin converting enzyme inhibitor, left anterior descending artery lesion, and electrocardiographic no-reflow were higher in Group 1. Admission hemoglobin levels were lower in Group 1. An RDW level $\geq 13.85 \%$ measured on admission had $80 \%$ sensitivity and $64 \%$ specificity in predicting long-term MACE on receiver-operating characteristic curve analysis. In multivariate analyses, only admission $R D W$ (HR 5.26, $<95 \%$ CI 1.71-16.10; $p=0.004$ ) was an independent predictor of long-term MACE.

Conclusions: A high baseline RDW value in patients with STEMI undergoing primary PCI is independently associated with increased risk for long term MACE. (Cardiol J 2016; 23, 3: 281-288)

Key words: red cell distribution width, ST-segment elevation myocardial infarction, long-term prognosis

Address for correspondence: Turgay Isik, MD, Department of Cardiology, Balikesir University, School of Medicine, Cagis Campus, Balikesir, Turkey, tel: +902666121010, fax: +902666121459, e-mail: isikturgay@yahoo.com 


\section{Introduction}

It is recommended to immediately re-perfuse the culprit artery with primary percutaneous coronary intervention (PCI) in ST-segment elevation myocardial infarction (STEMI). Despite significant prognostic improvements with newer treatment approaches and strategies in STEMI patients, incidence of adverse cardiovascular events (CVE) still remains significant in high risk patients both in hospital and long-term follow-up. Therefore, identification of the high-risk patients may have a leading role in application of additional pharmacological and mechanical treatment approaches providing prognostic benefits during and after the primary PCI. There are many studies in the literature showing that besides numerous demographic and clinical features, increased inflammation and oxidative stress are important determinants of prognosis in STEMI.

Red cell distribution width (RDW) is a routinely used measure as part of a standard complete blood count $(\mathrm{CBC})$ in clinical practice. $\mathrm{RDW}$ which is a measure of the variation in the size of circulating erythrocytes (anisocytosis) has been utilized in differential diagnosis of anemia [1]. In addition, increased levels of RDW are closely associated with inflammation [2-4], oxidative stress [5] and are related with poor prognoses in stable and unstable cardiac events [6-9].

Although a few studies have investigated the prognostic significance of RDW in STEMI patients, these studies were either retrospective or had a short follow-up. To the best of our knowledge, this is the first prospective study with longer followup time, investigating prognostic value of RDW in STEMI patients who underwent primary PCI.

\section{Methods}

\section{Study population}

A total of 135 patients with STEMI who underwent cardiac catheterization between September 2010 and December 2010 were included in this study. The patients who presented within $12 \mathrm{~h}(18 \mathrm{~h}$ for cardiogenic shock) of the onset of symptoms (typical chest pain lasting for $>30 \mathrm{~min}$ ) and having a ST-segment elevation $\geq 1 \mathrm{~mm}$ in at least two adjacent electrocardiography (ECG) leads were included in the study. We had to exclude some patients due to various reasons: 17 patients were excluded from the study because they had not undergone primary PCI and were treated conservatively or referred to surgery, 8 patients in whom we were unable to obtain long-term follow-up data, 4 patients due to a left ventricular hypertrophy result on baseline ECG which was defined as SokolowLyon voltages $>35 \mathrm{mV}, 4$ patients because of the presence of anemia at the time of admission, 2 patients due to new onset of complete left bundle branch block, 2 patients because of non-cardiac death, and 2 patients because they had been given thrombolytic therapy before the primary PCI. As a result, 96 non-anemic patients $(77.1 \%$ male and mean age $60.6 \pm 12.5$ ) with primary PCI were enrolled in the study. Patients were divided into two groups: 30 patients with long-term major adverse cardiac events (MACE, Group 1) and 66 patients without long-term MACE (Group 2). The study was approved by the Ethical Committee of our hospital; signed and informed written consents were received from all the patients included.

\section{Definitions}

Clinical characteristics of patients were recorded including age and gender, hypertension, hypercholesterolemia, diabetes mellitus (DM), history of coronary artery disease (CAD), smoking status, height, and weight. The body mass index was calculated by dividing body mass in kilograms by the square of the height in $\mathrm{m}^{2}\left(\mathrm{~kg} / \mathrm{m}^{2}\right)$. The diagnosis of DM was set based on previous history of DM treated with or without medication. Hypercholesterolemia was defined as total cholesterol $\geq 200 \mathrm{mg} / \mathrm{dL}$. Reperfusion time was defined as the time between onset of chest pain and inflation of the first balloon. Multi-vessel disease was defined as a stenosis $>50 \%$ in 2 or more major epicardial coronary arteries. A successful intervention was defined as a reduction in stenosis or obstruction to less than 50\% with Thrombolysis in Myocardial Infarction (TIMI) 2-3 flow after primary PCI. Premature discontinuation of clopidogrel therapy was defined as continued dual antiplatelet therapy for less than 1 year. Anemia on admission was defined according to the World Health Organization as baseline hemoglobin $(\mathrm{Hb})$ value $<13 \mathrm{mg} / \mathrm{dL}$ in men and $<12 \mathrm{mg} / \mathrm{dL}$ in women.

\section{Coronary angiography and PCI procedure}

Primary PCI procedure was carried out through standard femoral approach using a 7-French guiding catheter. After administration of 10,000 IU of heparin, $300 \mathrm{mg}$ acetylsalicylic acid (ASA) and $600 \mathrm{mg}$ clopidogrel loading dose conventional wire crossing, direct stenting (bare metal stents) was performed whenever possible, while balloon pre-dilatation was carried out in the remaining 
cases. Tirofiban was given concomitantly with the primary PCI, depending on operator's decision. Non-ionic low osmolality contrast agent was used in all patients. After angioplasty, all patients were admitted to the coronary care unit; $100 \mathrm{mg}$ ASA and $75 \mathrm{mg}$ clopidogrel were continued for all patients. Concomitant medical treatment with beta-blockers, angiotensin converting enzyme inhibitors (ACEI), and statins was prescribed according to American College of Cardiology/American Heart Association guidelines.

\section{Laboratory analysis, ECG and echocardiography}

In all patients, antecubital venous blood samples were collected in the emergency room for the laboratory analysis during admission. Hemoglobin, RDW and white blood cell count, as well as other hematologic indices, were measured as part of the CBC, using a Coulter LH 780 Hematology Analyzer (Beckman Coulter Ireland Inc., Mervue, Galway, Ireland). High sensitive C-reactive protein (hs-CRP) was measured through a BN2 model nephelometer (Dade-Behring).

Measurements were taken from the first ECG which was ordered immediately before angioplasty (STE 1) and from the second ECG which was obtained $60 \mathrm{~min}$ after PCI (STE 2). The sum of ST-segment elevation (sum STE) was calculated by adding all ST elevations present in leads I, aVL and V1 through V6 for anterior and in leads II, III, aVF, V5 and V6 for inferior infarctions [10]. The difference between STE 1 and STE 2 was then measured and accepted as the resolution of the sum of ST-segment elevation, expressed as sigma STR ( $\sum$ STR). Patients with $\sum$ STR $<50 \%$ were considered having electrocardiographic no-reflow phenomenon, based on the classification by Schroder et al. [11]. Transthoracic echocardiography was performed in all patients in the intensive cardiac care unit immediately after primary PCI through a system V (Vingmed; GE, Horten, Norway) using a $2.5 \mathrm{MHz}$ phased-array transducer. Measurements were were taken on patients at the position of left lateral decubitus. The left ventricular ejection fraction was measured using the modified Simpson's rule [12].

\section{Clinical endpoints}

All the patients were prospectively followed up for 48 months, and the evaluations in $48^{\text {th }}$ month were performed either on-site or via phone. The main endpoints assessed in this study included the MACE that were defined as cardiovascular mortal- ity, repeat target vessel revascularization (TVR) and reinfarction (re-MI). Cardiovascular mortality in patients was defined as death attributable to myocardial ischemia and infarction, heart failure, arrhythmia (ventricular fibrillation, ventricular tachycardia or asystole) and cardiac arrest because of other or unknown cause or cerebrovascular accident. TVR was defined as the requirement of $\mathrm{PCI}$ or coronary surgery in the target vessel driven by clinical symptoms such as the restenosis or re-occlusion of the infarct related artery. Re-MI was defined as a re-elevation in creatine kinase (CK) that was twice as high of the last value associated with $\mathrm{CK}-\mathrm{MB} \geq 10 \%$ of the total $\mathrm{CK}$ and ST-segment re-elevations [13].

\section{Statistics analysis}

Continuous variables are expressed as mean \pm standard deviation, while categorical variables are given as percentages. The Student's t-test was used in comparison of parametric continuous variables, Mann-Whitney U test in comparison of nonparametric continuous variables and the $\chi^{2}$ test for comparison of categorical variables. The cumulative survival curves for long-term MACE were constructed using the Kaplan-Meier method, while log-rank testing was used in evaluation of the differences between the RDW groups. Sensitivity and specificity of RDW, as well as its respective optimal cut-off value in prediction long-term MACE, were expressed through the receiver operating characteristics (ROC) curve. Multivariate Cox regression analysis was used in order to define the independent predictors of long-term MACE. All variables which showed significance values $<0.1$ on univariate analysis were included in the model. The RDW level was adjusted with $\mathrm{Hb}$ and all covariates in the Cox regression analysis. Two-tailed $\mathrm{p}$ values $<0.05$ were considered statistically significant in a confidence interval (CI) of 95\%. Statistical analyses were performed using the SPSS software (version 15.0, SPSS, Chicago, Illinois, USA).

\section{Results}

There were 30 patients (mean age $64.5 \pm 12.4$, $76.7 \%$ male) in Group 1 and 66 patients (mean age $58.9 \pm 12.3,77.3 \%$ male) in Group 2. Baseline characteristics are shown in Table 1 . Patients in the Group 1 were significantly older $(\mathrm{p}=0.03)$. There were no significant differences between the groups with regard to cardiovascular risk factors. With respect to baseline laboratory status, 
Table 1. Baseline characteristics of patients with and without long-term major adverse cardiac events (MACE).

\begin{tabular}{|c|c|c|c|}
\hline & Group $1(n=30)$ & Group $2(n=66)$ & $\mathbf{P}$ \\
\hline Age [years] & $64.5 \pm 12.4$ & $58.9 \pm 12.3$ & 0.03 \\
\hline Male gender & $23(76.7 \%)$ & $51(77.3 \%)$ & 0.57 \\
\hline Hypertension & $13(43.3 \%)$ & $20(30.3 \%)$ & 0.16 \\
\hline Diabetes mellitus & $4(13.3 \%)$ & $12(18.2 \%)$ & 0.39 \\
\hline Hypercholesterolemia & $9(30.0 \%)$ & $20(30.3 \%)$ & 0.59 \\
\hline Smoking & $15(50.0 \%)$ & $38(57.6 \%)$ & 0.32 \\
\hline Previous CAD & $6(20.0 \%)$ & $13(19.7 \%)$ & 0.59 \\
\hline Body mass index $\left[\mathrm{kg} / \mathrm{m}^{2}\right]$ & $25.9 \pm 5.2$ & $26.6 \pm 3.7$ & 0.34 \\
\hline Hs-CRP $[\mathrm{mg} / \mathrm{dL}]$ & $12.1 \pm 10.2$ & $6.06 \pm 5.4$ & 0.003 \\
\hline LVEF on admission [\%] & $42.3 \pm 9.5$ & $43.6 \pm 10.9$ & 0.48 \\
\hline Serum glucose [mg/dL] & $154.3 \pm 76.6$ & $155.5 \pm 68.0$ & 0.83 \\
\hline Admission CK-MB [U/L] & $148.51 \pm 123.54$ & $86.76 \pm 93.03$ & 0.005 \\
\hline Hemoglobin $[\mathrm{g} / \mathrm{dL}]$ & $14.7 \pm 2.1$ & $15.8 \pm 1.4$ & 0.01 \\
\hline Platelet $\left[\mathrm{mm}^{3}\right]$ & $248.0 \pm 64.9$ & $250.2 \pm 63.9$ & 0.89 \\
\hline White blood cell $\left[10^{3} / \mu \mathrm{L}\right]$ & $12.5 \pm 4.1$ & $12.3 \pm 4.2$ & 0.76 \\
\hline Mean platelet volume [fL] & $8.2 \pm 1.1$ & $8.0 \pm 1.0$ & 0.42 \\
\hline Red cell distribution width [\%] & $14.9 \pm 1.3$ & $13.6 \pm 0.6$ & $<0.001$ \\
\hline \multicolumn{4}{|l|}{ Hemodynamic data pre-PCl: } \\
\hline Systolic BP [mm Hg] & $133.7 \pm 26.5$ & $132.7 \pm 30.9$ & 0.72 \\
\hline Diastolic BP [mm Hg] & $84.1 \pm 16.5$ & $86.6 \pm 16.0$ & 0.31 \\
\hline Heart rate $[\mathrm{bpm}]$ & $86.5 \pm 19.7$ & $79.9 \pm 20.7$ & 0.11 \\
\hline \multicolumn{4}{|l|}{ Hemodynamic data after $\mathrm{PCl}$} \\
\hline Systolic BP [mm Hg] & $118.5 \pm 32.7$ & $119.8 \pm 22.5$ & 0.72 \\
\hline Diastolic BP [mm Hg] & $77.8 \pm 17.4$ & $77.5 \pm 17.4$ & 0.80 \\
\hline Heart rate $[\mathrm{bpm}]$ & $85.3 \pm 15.8$ & $76.9 \pm 17.8$ & 0.03 \\
\hline Creatinine $[\mathrm{mg} / \mathrm{dL}]$ & $0.91 \pm 0.26$ & $0.87 \pm 0.24$ & 0.33 \\
\hline Uric acid $[\mathrm{mg} / \mathrm{dL}]$ & $4.7 \pm 2.1$ & $4.8 \pm 1.4$ & 0.31 \\
\hline \multicolumn{4}{|l|}{ Previous medications: } \\
\hline Acetylsalicylic acid & $6(20.0 \%)$ & $9(13.6 \%)$ & 0.30 \\
\hline Beta-blockers & $2(6.7 \%)$ & $7(10.6 \%)$ & 0.42 \\
\hline ACEI & $8(26.7 \%)$ & $6(9.1 \%)$ & 0.03 \\
\hline Statin therapy & $1(3.3 \%)$ & $4(6.1 \%)$ & 0.50 \\
\hline Diuretic & $1(3.3 \%)$ & $2(3.0 \%)$ & 0.68 \\
\hline Calcium channel blockers & $3(10.0 \%)$ & $4(6.1 \%)$ & 0.38 \\
\hline \multicolumn{4}{|l|}{ Long term medications: } \\
\hline Acetyl-salicylic acid & $27(90 \%)$ & $62(93.4 \%)$ & 0.38 \\
\hline Premature discontinuation of clopidogrel therapy & $5(16.7 \%)$ & $3(4.6 \%)$ & 0.06 \\
\hline Beta-blockers & $20(66.7 \%)$ & $47(71.2 \%)$ & 0.41 \\
\hline ACEI & $19(63.3 \%)$ & $43(65.2 \%)$ & 0.51 \\
\hline Statin therapy & $18(60 \%)$ & $42(63.6 \%)$ & 0.45 \\
\hline Diuretic & $11(36.7 \%)$ & $23(34.8 \%)$ & 0.51 \\
\hline Calcium channel blockers & $13(43.3 \%)$ & $26(39.4 \%)$ & 0.44 \\
\hline Multivessel disease & $19(63.3 \%)$ & $31(47.0 \%)$ & 0.10 \\
\hline Infarct related artery: & & & 0.04 \\
\hline LAD & $19(63.3 \%)$ & $27(40.9 \%)$ & \\
\hline $\mathrm{CX}$ & $6(20 \%)$ & $8(12.1 \%)$ & \\
\hline $\mathrm{RCA}$ & $5(16.7 \%)$ & $31(47 \%)$ & \\
\hline Reperfusion time [h] & $4.7 \pm 2.1$ & $4.6 \pm 1.9$ & 0.73 \\
\hline Stent implanted & $27(90.0 \%)$ & $59(89.4 \%)$ & 0.62 \\
\hline Stent length [mm] & $17.9 \pm 5.7$ & $19.9 \pm 6.1$ & 0.16 \\
\hline Stent diameter $[\mathrm{mm}]$ & $3.05 \pm 0.25$ & $3.13 \pm 0.29$ & 0.31 \\
\hline Tirofiban administered & $23(76.7 \%)$ & $44(66.7 \%)$ & 0.23 \\
\hline Electrocardiographic no-reflow & $14(46.7 \%)$ & $15(22.7 \%)$ & 0.02 \\
\hline Angiographic failure & $7(23.3 \%)$ & $6(9.1 \%)$ & 0.06 \\
\hline Cardiovascular mortality & $20(66.7 \%)$ & & \\
\hline Repeat target vessel revascularization & $15(50 \%)$ & & \\
\hline Reinfarction & $20(66.7 \%)$ & & \\
\hline
\end{tabular}

Data are expressed as mean \pm standard deviation for continuous variables and percentages $\mathrm{n}$ (\%) for categorical variables; CAD - coronary artery disease; hs-CRP — high sensitive C reactive protein; LVEF - left ventricular ejection fraction; CK-MB - creatinine kinase-MB; $\mathrm{PCl}$ - percutaneous coronary intervention; BP — blood pressure; ACEI — angiotensin converting enzyme inhibitors; LAD - left anterior descending; CX — circumflex coronary artery; RCA — right coronary artery; Group 1 - patients with MACE; Group 2 - patient without MACE 
while admission hs-CRP ( $\mathrm{p}=0.003)$, CK-MB $(\mathrm{p}=0.005)$ and RDW $(\mathrm{p}<0.001)$ were significantly higher in Group 1, admission $\mathrm{Hb}$ was significantly lower $(\mathrm{p}=0.01)$. Heart rate after PCI $(p=0.03)$, previously used an ACEI $(p=0.03)$, left anterior descending artery lesion $(\mathrm{p}=0.03)$ and electrocardiographic no-reflow $(\mathrm{p}=0.02)$ were significantly higher in Group 1 . There were $20(66.7 \%)$ patients with cardiovascular mortality, $15(50 \%)$ patients with TVR and $20(66.7 \%)$ patients with re-MI in Group I patients.

The ROC curves of RDW for predicting long-term MACE is shown in Figure 1. A RDW $\geq 13.85 \%$ measured on admission had $80 \%$ sensitivity and $64 \%$ specificity in predicting long-term MACE.

In the multivariate analyses for long-term MACE, age, Hb, RDW, hs-CRP, CK-MB on admission, previously used an ACEI, premature discontinuation of clopidogrel therapy, heart rate after PCI, left anterior descending artery lesion, presence of electrocardiographic no-reflow, and angiographic failure were analyzed with multivariate Cox regression model. Only RDW (HR 5.26, < 95\% CI $1.71-16.10, p=0.004$ ) was still independent predictors of long-term MACE, even after adjustment for $\mathrm{Hb}$ (Tables 2, 3). Kaplan-Meier survival plots for MACE in RDW groups are presented in Figure 2.

\section{Discussion}

This is the first prospective study investigating the relationship between the admission levels of RDW and long-term CVE in STEMI patients who

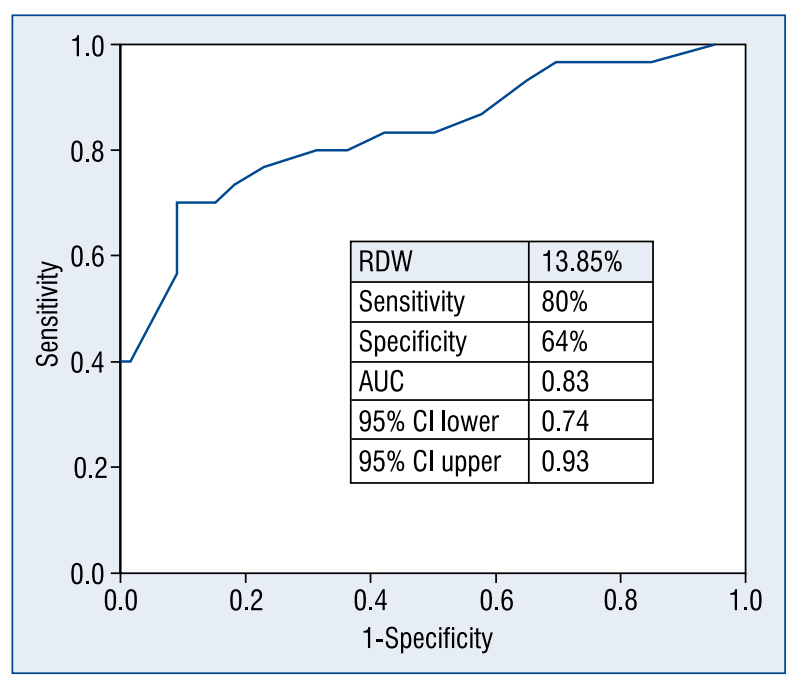

Figure 1. The receiver-operating characteristic curve of red cell distribution width (RDW) for predicting long-term major adverse cardiac events; AUC — area under curve; $\mathrm{Cl}$ - confidence interval.

underwent primary PCI. In the present study, we demonstrated that a higher baseline RDW levels were an independent predictor of 48 -month cardiovascular outcomes in STEMI patients.

Red cell distribution width, which is a part of standard $\mathrm{CBC}$, is a quantitative measure of the variations in the size of circulating erythrocytes. Clinical use of RDW has usually been confined to the differential diagnosis of anemia and hematological disorders. Elevated RDW typically indicates increased destruction of red cells or nutritional de-

Table 2. Effects of various variables on long-term major adverse cardiac events in univariate and multivariate Cox regression analyses.

\begin{tabular}{lcccccc}
\hline & Univariate HR & $95 \%$ Cl & P & Multivariate HR & $95 \%$ Cl & P \\
\hline Age & 1.03 & $1.01-1.07$ & 0.03 & 1.03 & $0.97-1.09$ & 0.28 \\
Hemoglobin & 0.79 & $0.68-0.93$ & 0.004 & 0.94 & $0.59-1.48$ & 0.80 \\
Red cell distribution width & 1.84 & $1.50-2.26$ & $<0.001$ & 5.26 & $1.71-16.10$ & 0.004 \\
Hs-CRP & 1.06 & $1.03-1.10$ & $<0.001$ & 0.98 & $0.88-1.09$ & 0.76 \\
Admission CK-MB & 1.00 & $1.00-1.01$ & 0.001 & 1.00 & $0.99-1.01$ & 0.33 \\
Previously used an ACEI & 3.63 & $1.13-11.66$ & 0.03 & 2.84 & $0.44-18.10$ & 0.26 \\
Premature discontinuation & 0.23 & $0.05-1.07$ & 0.06 & 8.26 & $0.71-95.91$ & 0.09 \\
of clopidogrel therapy & & & & & & \\
After-PCl heart rate & 1.02 & $1.00-1.05$ & 0.03 & 1.03 & $0.98-1.07$ & 0.15 \\
LAD lesion & 0.44 & $0.21-0.93$ & 0.03 & 0.28 & $0.06-1.35$ & 0.11 \\
Electrocardiographic no-reflow & 2.51 & $1.22-5.16$ & 0.01 & 2.07 & $0.46-9.25$ & 0.33 \\
Angiographic failure & 2.17 & $0.93-5.05$ & 0.08 & 3.07 & $0.42-22.14$ & 0.26 \\
\hline
\end{tabular}

$\mathrm{HR}$ - hazard ratio; $\mathrm{Cl}$ - confidence interval; hs-CRP — high sensitive $\mathrm{C}$ reactive protein; $\mathrm{CK}-\mathrm{MB}$ - creatine kinase $\mathrm{MB}$; $\mathrm{ACEI}$ - angiotensin converting enzyme inhibitor; $\mathrm{PCI}$ - percutaneous coronary intervention; $\mathrm{LAD}$ - left anterior descending 
Table 3. Cox regression analysis of major adverse cardiac events (MACE) in overall population for red cell distribution width levels.

\begin{tabular}{|c|c|c|c|c|c|c|}
\hline \multirow[t]{2}{*}{ Outcome } & \multicolumn{2}{|c|}{ Unadjusted } & \multicolumn{2}{|c|}{ Adjusted for $\mathrm{Hb}$} & \multicolumn{2}{|c|}{ Adjusted for $\mathrm{Hb}$ and all covariates* } \\
\hline & HR (95\% CI) & $\mathbf{P}$ & HR (95\% CI) & $\mathbf{P}$ & HR $(95 \% \mathrm{CI})$ & $\mathbf{P}$ \\
\hline MACE & $1.84(1.50-2.26)$ & $<0.001$ & $6.63(2.82-15.58)$ & $<0.001$ & $5.26(1.71-16.10)$ & 0.004 \\
\hline
\end{tabular}

*Adjusted for age, high sensitive C-reactive protein, left anterior descending artery lesion, creatine kinase-MB on admission, heart rate after percutaneous coronary intervention, previously used an angiotensin converting enzyme inhibitor, premature discontinuation of clopidogrel therapy, presence of electrocardiographic no-reflow and angiographic failure in the analysis; $\mathrm{HR}-\mathrm{hazard}$ ratio; $\mathrm{Cl}-\mathrm{confidence}$ interval; $\mathrm{Hb}-$ hemoglobin

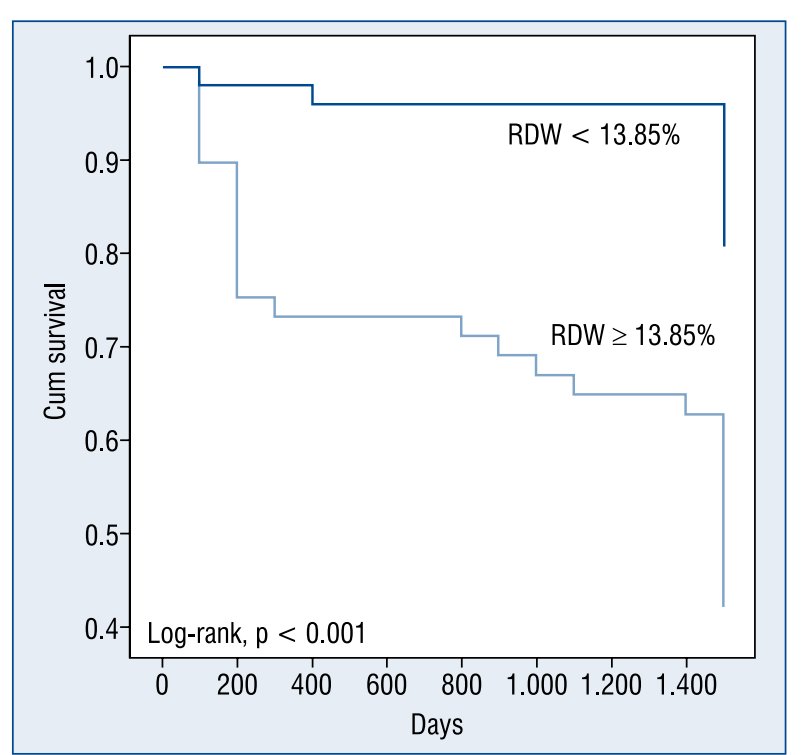

Figure 2. Kaplan-Meier curves for long-term major adverse cardiac events in patients with red cell distribution width $(\mathrm{RDW})<13.85 \%$ and $\mathrm{RDW} \geq 13.85 \%$.

ficiency such as vitamin B12, iron, and folate, or is observed after blood transfusion. In addition, many recently published studies reported that increased RDW levels are correlated with poor prognosis in many acute-chronic cardiac and non-cardiac events $[7,9,14]$, even in the case of adjustments for multiple potential confounders, including anemia. In a study by Uyarel et al. [7], high RDW level on admission was demonstrated to be an indicator for in-hospital and long-term cardiovascular mortality in STEMI patients who underwent primary PCI. The authors revealed that increased age, Killip class $>1$, DM, and high RDW were found to be predictors of cardiovascular mortality [7]. Unlike our study, these authors used a retrospective database. In the present study, we showed high RDW levels were independently associated with increased risk for long-term MACE. In a prospective study, Gul et al. [15] showed that high RDW levels were as- sociated with long-term cardiovascular mortality in patients with non-STEMI and unstable angina pectoris. Van Kimmenade et al. [16] demonstrated that high RDW level was an independent indicator of 1-year mortality in acute cardiac failure. Similar to unstable cardiac events, RDW has been shown to have prognostic value also in stable cardiovascular conditions. For example, Lappe et al. [2] demonstrated that RDW was associated with mortality in patients with stable CAD. Increased RDW levels have been demonstrated to have prognostic implication not only in cardiac conditions, but also in many non-cardiac events even in healthy and elderly populations [17].

Because RDW is a reflection of conditions that increases cardiovascular risk, it is a prognostic indicator for both cardiac and non-cardiac events. Increased risk related to RDW levels results from increased inflammation, oxidative stress and neurohormonal transmission both in cardiac and non-cardiac events. Like in the case when a car which gets out of control may cause undesirable conditions, over increased inflammation and oxidative stress in our body leads to undesirable outcomes. As a result of changes, they exerted on erythrocytes; increased inflammation [2,3], oxidative stress [5] and neurohormonal activation [18] lead to different size of erythrocytes to involve in the circulation, namely anisocytosis. Possible contribution of inflammation to anisocytosis results from inhibition of the response production against erythropoietin, impaired iron metabolism, and shortened time of red blood cell survival [19]. In addition, it has been found in previous studies that inflammatory cytokines suppress the maturation of erythrocytes, therefore immature erythrocytes which enter the circulation may accelerate erythropoiesis [20]. Previously, we published first outcomes of this study and demonstrated that there was a good correlation between hs-CRP level, which is an important inflammatory marker and RDW level on admission [21]. Oxidative stress 
was suggested as another mechanism of prognostic value of RDW [22,23]. Red blood cells have a powerful antioxidant capacity and function as a primary oxidative sink; they are prone to oxidative damage which decreases cell survival and they increase the release of juvenile erythrocytes into circulation. Consequently, we suggest that the link between increased oxidative stress and inflammatory activation and elevated RDW value is closely related with prognosis in STEMI. No wonder, it is not enough to attribute the association between increased RDW level and poor prognosis to the increased stress alone. It is well known that there is a close relationship between increased levels of RDW and many conditions that have prognostic importance in cardiovascular disease including coronary complexity [24], impaired renal function [25], and altered hematological features, such as increased total blood viscosity which could pose substantial changes in the blood flow [26]. Another important relationship is the close correlation between increased RDW level and inadequate tissue perfusion (no-reflow). With the first outcomes of our previous study, we demonstrated that increased RDW levels were closely correlated with electrocardiographic no-reflow which was an independent predictor of mortality after PCI. There are numerous studies demonstrating a close correlation between RDW and no-reflow, and RDW being a good marker of short- and long-term CVE, although evidence for the prognostic significance of no-reflow outweighs especially in the early period, the correlation between no-reflow and long-term prognosis remains controversial [27]. In fact, in our study we found that unlike RDW, electrocardiographic no-reflow was not an independent indicator of long-term MACE, suggesting that RDW level was a common reflection defined not only by no-reflow, but also by the other cardiac risk factors.

The pathophysiological mechanistic link which drives this correlation remains obscure at the time of this study and a more thorough insight into the physiological mechanism is needed. Nevertheless, theoretically, we believe that inflammatory activation and oxidative stress, which are accepted as risk factors for CVE influence the erythropoiesis and thus result in elevated levels of RDW.

\section{Limitations of the study}

This study has some possible limitations. First, the study was conducted in a single center with only a small number of patients. However, our study population included homogeneous unselected STEMI patients who underwent primary
PCI; therefore, the real world scenario was able to be represented. Second, $\Sigma$ STR which is an indirect method for detecting myocardial perfusion was used. Quantitative myocardial contrast echocardiography method is able to provide more detailed information about tissue perfusion. In addition, myocardial blush grade was not assessed due to the fact that the optimal cineangiographic frame count setting $(12.5 \mathrm{Fr} / \mathrm{s})$ was not available. $\Sigma$ STR measurements conventionally obtained from a blinded manual were highly reproducible, but measurements to be conducted by a digital ECG system with a highresolution screen might be more reliable. Third, elevated RDW levels are observed in many clinical settings including increased red cell destruction after transfusion, hemolysis and in the setting of ineffective red cell production such as that of iron deficiency, vitamin B12 or folate. Levels of RDW are also elevated during several clinical conditions such as inflammatory bowel diseases, thrombotic thrombocytopenic purpura and pregnancy [28-30]. Hemoglobin was the only measured factor in this study, while other factors were not measured, including vitamin B12, iron and folate. Blood transfusion was not carried out in any of our patients, while there was no pregnant, inflammatory bowel disease, thrombotic thrombocytopenic purpura or malnourished patients in this study.

\section{Conclusions}

Red cell distribution width is a marker indicating long-term prognosis in STEMI patients undergoing primary PCI, which is easily accessible and causes no additional cost.

\section{Acknowledgements}

The authors are the only responsible persons for the design and conduct, analyses, drafting and editing, and final contents of the study.

\section{Conflict of interest: None declared}

\section{References}

1. Abbate A, Bonanno E, Mauriello A et al. Widespread myocardial inflammation and infarct-related artery patency. Circulation, 2004; 110: 46-50.

2. Lappe JM, Horne BD, Shah SH et al. Red cell distribution width, C-reactive protein, the complete blood count, and mortality in patients with coronary disease and a normal comparison population. Clin Chim Acta, 2011; 412: 2094-2099.

3. Lippi G, Targher G, Montagnana M, Salvagno GL, Zoppini G, Guidi GC. Relation between red blood cell distribution width and inflammatory biomarkers in a large cohort of unselected outpatients. Arch Pathol Lab Med, 2009; 133: 628-632. 
4. Jackson CE, Dalzell JR, Bezlyak V et al. Red cell distribution width has incremental prognostic value to B-type natriuretic peptide in acute heart failure. Eur J Heart Fail, 2009; 11: 1152-1154 .

5. Semba RD, Patel KV, Ferrucci L et al. Serum antioxidants and inflammation predict red cell distribution width in older women: The Women's Health and Aging Study I. Clin Nutr, 2010; 29: 600-604.

6. Tonelli M, Sacks F, Arnold M, Moye L, Davis B, Pfeffer M. Relation between red blood cell distribution width and cardiovascular event rate in people with coronary disease. Circulation, 2008; 117: 163-168.

7. Uyarel H, Ergelen M, Cicek G et al. Red cell distribution width as a novel prognostic marker in patients undergoing primary angioplasty for acute myocardial infarction. Coron Artery Dis, 2011; 22: 138-144.

8. Montagnana M, Cervellin G, Meschi T, Lippi G. The role of red blood cell distribution width in cardiovascular and thrombotic disorders. Clin Chem Lab Med, 2012; 50: 635-641.

9. Forhecz Z, Gombos T, Borgulya G, Pozsonyi Z, Prohaszka Z, Janoskuti L. Red cell distribution width in heart failure: Prediction of clinical events and relationship with markers of ineffective erythropoiesis, inflammation, renal function, and nutritional state. Am Heart J, 2009; 158: 659-666.

10. Schroder R, Dissmann R, Bruggemann T et al. Extent of early ST segment elevation resolution: A simple but strong predictor of outcome in patients with acute myocardial infarction. J Am Coll Cardiol, 1994; 24: 384-391.

11. Schroder R. Prognostic impact of early ST-segment resolution in acute ST-elevation myocardial infarction. Circulation, 2004; 110: e506-510.

12. Schiller NB, Shah PM, Crawford M et al. Recommendations for quantitation of the left ventricle by two-dimensional echocardiography. American Society of Echocardiography Committee on Standards, Subcommittee on Quantitation of Two-Dimensional Echocardiograms. J Am Soc Echocardiogr, 1989; 2: 358-367.

13. Ergelen M, Gorgulu S, Uyarel H et al. Prediction of cardiovascular mortality in patients with ST-elevation myocardial infarction after primary percutaneous coronary intervention. Coron Artery Dis, 2010; 21: 207-211.

14. Patel KV, Ferrucci L, Ershler WB, Longo DL, Guralnik JM. Red blood cell distribution width and the risk of death in middle-aged and older adults. Arch Intern Med, 2009; 169: 515-523.

15. Gul M, Uyarel H, Ergelen $M$ et al. The relationship between red blood cell distribution width and the clinical outcomes in non-ST elevation myocardial infarction and unstable angina pectoris: A 3-year follow-up. Coron Artery Dis, 2012; 23: 330-336.

16. van Kimmenade RR, Mohammed AA, Uthamalingam S, van der Meer P, Felker GM, Januzzi JL, Jr. Red blood cell distribution width and 1-year mortality in acute heart failure. Eur J Heart Fail, 2010; 12: 129-136.

17. Patel KV, Semba RD, Ferrucci L et al. Red cell distribution width and mortality in older adults: A meta-analysis. J Gerontol A Biol Sci Med Sci, 2010; 65: 258-265.

18. Fukuta H, Ohte N, Mukai S et al. Elevated plasma levels of $\mathrm{B}$-type natriuretic peptide but not $\mathrm{C}$-reactive protein are associated with higher red cell distribution width in patients with coronary artery disease. Int Heart J, 2009; 50: 301-312.

19. Weiss G, Goodnough LT. Anemia of chronic disease. N Engl J Med, 2005; 352: 1011-1023.

20. Pierce CN, Larson DF. Inflammatory cytokine inhibition of erythropoiesis in patients implanted with a mechanical circulatory assist device. Perfusion, 2005; 20: 83-90.

21. Isik T, Kurt M, Ayhan E, Tanboga IH, Ergelen M, Uyarel H. The impact of admission red cell distribution width on the development of poor myocardial perfusion after primary percutaneous intervention. Atherosclerosis, 2012; 224: 143-149.

22. Allen LA, Felker GM, Mehra MR et al. Validation and potential mechanisms of red cell distribution width as a prognostic marker in heart failure. J Card Fail, 2010; 16: 230-238.

23. Wen Y. High red blood cell distribution width is closely associated with risk of carotid artery atherosclerosis in patients with hypertension. Exp Clin Cardiol, 2010; 15: 37-40.

24. Isik T, Uyarel H, Tanboga IH et al. Relation of red cell distribution width with the presence, severity, and complexity of coronary artery disease. Coron Artery Dis, 2012; 23: 51-56.

25. Lippi G, Targher G, Montagnana M, Salvagno GL, Zoppini G, Guidi GC. Relationship between red blood cell distribution width and kidney function tests in a large cohort of unselected outpatients. Scand J Clin Lab Invest, 2008; 68: 745-748.

26. Savov Y, Antonova N, Zvetkova E, Gluhcheva Y, Ivanov I, Sainova I. Whole blood viscosity and erythrocyte hematometric indices in chronic heroin addicts. Clin Hemorheol Microcirc, 2006; 35: 129-133.

27. Choo EH, Kim PJ, Chang $\mathrm{K}$ et al. The impact of no-reflow phenomena after primary percutaneous coronary intervention: A time-dependent analysis of mortality. Coron Artery Dis, 2014; 25: 392-398.

28. Clarke K, Sagunarthy R, Kansal S. RDW as an additional marker in inflammatory bowel disease/undifferentiated colitis. Dig Dis Sci, 2008; 53: 2521-2523.

29. Shehata HA, Ali MM, Evans-Jones JC, Upton GJ, Manyonda IT. Red cell distribution width (RDW) changes in pregnancy. Int J Gynaecol Obstet, 1998; 62: 43-46.

30. Nagajothi N, Braverman A. Elevated red cell distribution width in the diagnosis of thrombotic thrombocytopenic purpura in patients presenting with anemia and thrombocytopenia. South Med J, 2007; 100: 257-259. 